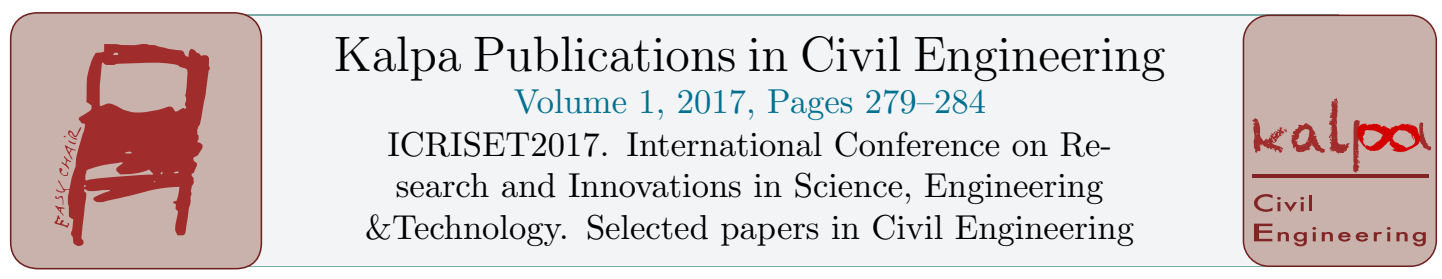

\title{
Effect of Bus Rapid Transit System on Urban Corridor
}

\author{
Divyesh Patel ${ }^{1 *}$ and Rena Shukla ${ }^{2 \dagger}$ \\ ${ }^{1,2}$ L.D. College of Engineering, Ahmedabad, Gujrat, India \\ pateldivyesh887@gmail.com, shukla_rena@yahoo.co.in
}

\begin{abstract}
This paper reviews traffic congestion problem and its solutions. BRTS become attractive and effective solution which is adopted in many countries. The aim of the present paper is to describe effect of BRTS which is the sustainable solution for public transport services in urban area. Various study carried out to developed guidelines for implementation of BRTS for different countries. Each country having different BRTS features as well as its impact also. The impact can be measure by micro-simulation before implementation of BRTS. Simulation gives realistic result under real world application.
\end{abstract}

\section{Introduction}

Traffic is the element of transport system which involves the travel of discrete units having characteristics of independence, randomness and human control. traffic characteristics are classified based Measurements of quantity (Density and flow), Measurements of quality (speed). The global percentage of urban population has been steadily increasing in the twentieth century. in India more than $60 \%$ of the world population will be living in urban areas in the year 2030 (statics World helth organisation, 2016).

Due to rapid growth in Urbanization and industrialization also increases in travel demand. As urbanization increase the mobility facility and infrastructure also increase. To minimize or eliminate

*P.G. Student

${ }^{\dagger}$ Associate Professor and P.G. Student advisor

C.D. Modhera, G.J. Joshi, D. Soni, I.N. Patel, A.K. Verma, L.B. Zala, S.D. Dhiman, D.R. Bhatt, J.M. Rathod, B.C. Goradiya, M.S. Holia and D.K. Patel (eds.), ICRISET2017 (Kalpa Publications in Civil Engineering, vol. 1), pp. 279-284 
this kind of problem proper traffic management by providing efficient road infrastructure facility and mobility should be requiring.

\section{Concept of Bus rapid transit system}

As per Federal Transit Administration BRTS has been defined as a rapid mode of transportation that can provide the quality of rail transit and the flexibility of buses. "Bus Rapid Transit" means a high-capacity urban public-transit system with separate right of way, and longer stops spacing than traditional buses. BRT system having different type of rights-of-way like mixed traffic right way, dedicated lanes based, and bus ways separated from traffic. BRT system has specialized design of its features and infrastructure to improve the transportation quality as well as remove delay also.

BRT System is widely developed in many new cities. At present total 156 cities implement BRT System in the world. Total passenger travel in BRTS is 2,56,44,130 per day. total length of BRTS route is 4036 . In India total 19 city accepted BRT System out of these in 8 city BRTS in operational condition, in 7 cities under implementation and in 5 city have DPR under preparation )Dr.shivanand, 2014(

BRT system proposals were developed for Chicago, United States in 1937 in which rubber tyre concept for bus is introduced. In 1937 plan of BRT system prepared in which three rail rapid-transit lines was converting to express bus operation in central areas and also in some portion of downtown area of the city (Harrington, 1937). During 1956-1959 Design of BRTS right of way (freeway medians) were developed as part of the "Mass Transportation Survey for the National Capital Region" in Washington D.C. It was recommended that planning of Bus Rapid Transit System as radial freeways a section which gives maximum flexibility to movement of buses and retains or secure the capacity for vehicles as well as for the mass movement of people. The 1959 Transportation plan included an 86-mile route of BRT system, in which 42 miles' route lengths were to be grade-separated type bus way having three lanes. Barton-Ashman Associates proposed in 1970 Milwaukie's (U.S.) transit-way plan in which 107 miles of express bus routes having freeway type BRT system and 8mile route lengths are transit-way type (Barton-Ashman Associates, 1971). The plan was integrated with existing and proposed freeways.

A 1970 study, Wilbur Smith sates that factor which Potential for Bus Rapid Transit are capital cost, operating cost, route configuration and distribution of route in city having greater impact in the center of city and also in major activity centers. They also concluded that freeway systems of express buses need modification, as provision exclusive bus lanes (Wilbur Smith and Associates, , 1970).

A 1975 study, Levinions introduced the concept of bus priority and multi-door articulated buses. This type of system reliable option for Bus Rapid Transit system in densely developed urban area (L. Goodman, 1972) (Levinson, 1973). Most of BRTS planning studies focused on the urban freeways 
of BRTS, Little or no attention was given to the station size, spacing, and service in buses as well as on stations of BRTS.

In 1996 study by AAMA (American Automobile manufacturer association) indicate that BRTS suitable in fast growing urban area and also attract the visitors towards the public transport. It indicates that BRT is the best and reliable public transport having lower capital costs and it provides greater coverage in low and medium-density areas. They also observed that due to implementation of BRTS land-use and population patterns also changed

In 2003, to analyze the effect of Bus Rapid Transit system and prepare the guidelines for implementation of BRTS total 26 cities are selected for a case study in world by transport research board (TRB) )Transit cooperative reserch programe, , 2003(). Out of 26 cities 12 cities from united states, 2 cities from Canada, 3 cities from Australia, 3 from Sydney, 6 from south Africa. The above all cities found in urban area having population 7,00,000. All cities having different criteria of BRT system facility. In most of cities running ways are starting from city center and its extending in a radial way. In North America (Boston and Seattle) and in Australia (Brisbane) bus tunnel type running way implemented. In new British and lottery (North America), Adelaide (Australia) separate right of way provided for BRT System. In Hosten(Germany), Los Angeles (U.S.), New York freeway bus lane is provided. Station spacing was also different in different cities. Out of the all case studies results shows that in most of city BRT does work effectively and having good impact. New passengers attracted towards BRT system. Land use pattern and economic development of urban area has been change due to transit oriented BRTS development. As compare to rail transit provision of integrated BRTS experience batter ridership in small to medium type cities. In Los Angeles metro rapid bus service additional trip $30 \%$ increase in terms of passengers who are not use existing transit system. So they concluded that BRTS make positive development effects. Ottawa (Canada), Pittsburgh, and Brisbane (Australia) have suggested that BRT investment make positive connection between the location of BRTS in city and design of new land development.

BRTS gives sufficient capacities of travel demand to meet peak-hour travel demands in most corridors in the city of United States and Canada. If separate running way or right of way provide for BRTS it gives reliably high speeds. The cost of BRT implementation, operating and maintenance are generally less than those of rail rapid transit, but developing cost of an effective BRT system is not always less as compare to light rail transit in medium size population area. It this case study it is found that BRT is an integral part of economic development, land use pattern, transportation, planning efforts. it is expected that implementation of integrated BRT systems leads to increase in future. There is difficult to keeping all elements of BRT system together in an integrated package and challenging to implement, Because limitation like financial and implementation of physical components. They also concluded that to attract ridership for communities towards BRTS, there is need to improve the existing bus pattern and its other features (Transit cooperative reserch programe, , 2003) 
In 2007 Vaishali M Patankar had study the impact of BRT system on traffic and commuter mobility and concluded that dedicated lane-based BRT system gives effectively results on densely urban area and has to play a significant role in development of sustainable transport systems in congested area (Vaishali M. patanakar, Rakesh kumar, , June 2007).V. Thamizh Arasan and p. Vedagiri (2009) states that introduction of bus rapid transit system on urban corridor enhance good level of service of bus as well as for other vehicles on the adjacent right of way. And also conclude that developed simulation model HETROSIM can simulate heterogeneous traffic flow on midblock stretch only (V. thamiz arasan and P. vedagiri, 2010). Tuhin Subhra (2010) had formulated methodology for selection of bus rapid transit corridors as the link or road way which has higher volume by capacity ratio is given priority in Hyderabad city. Gautam Raj Godavarthi had measured the "the performance of bus rapid transit corridor based on volume by capacity ratio". They concluded that $\mathrm{v} / \mathrm{c}$ ratio up to 0.688 give reliable speed and minor delay. If $\mathrm{v} / \mathrm{c}$ ratio is beyond 0.688 than it creating traffic congestion in both BRTS lane as well as in MV lane (Guatam raj godavarthi, 2014).Pavar Utsav stated that decrease in delay is observed at every intersection compared to pre to post BRTS situation. User feedback survey indicates that BRT system is good for city (Dr.H.R.Varia, 2012)

Chetan R Patel (2012) had developed speed flow relationship for two different regimes as (1) free flow condition (2) congested flow condition. They concluded that establish flow speed relationship will be ideal for access control arterial road (Chetan R. patel and DR. G.J.joshi , 2012).

Rakesh Kumar and Fatima (2014) examine that possible modal shift to proposed public transit system was range from $45 \%$ to $51 \%$. They also concluded that introduction of new public transit system gives good or improve the level of service )Electricwala Fatima, Rakesh Kumar, 2014(.

Bhanu Kireeti Chanda (2014) suggest that implement of BRT or LRT to improve level of service (Bhanu kireeti chanda and maddali sai satya goutham, 2014). V Sampath Kumar (2016) states that After implementation of BRTS there is improvement in LOS F to LOS B OR C and elevated BRTS system suitable for some of location (Smpath kumar, v ranjit kumar,DR. M.kameshwararao, 2016).

\section{Summary}

In past numbers of solution developed to minimize the traffic congestion like increase the capacity of road, provide public transit system etc. Provision of public transportation is the one of the most effective solution of traffic congestion problem. But before implementation there is need to evaluate the effect of the proposed system by computer simulation at micro level so the error of the system can be minimizing during planning, design and implementation time. 
Table 1 Effect of BRT System

\begin{tabular}{|c|c|c|}
\hline $\begin{array}{l}\text { Sr. } \\
\text { no. }\end{array}$ & Case study & Effect/Conclusion \\
\hline 1 & $\begin{array}{l}1970 \\
\text { Weber }\end{array}$ & $\begin{array}{l}\text { Freeway systems of buses need modification, as provision } \\
\text { exclusive bus lanes. }\end{array}$ \\
\hline 2 & $\begin{array}{c}1975 \\
\text { Levinsions }\end{array}$ & $\begin{array}{l}\text { BRTS is reliable option in densely developed urban area and need } \\
\text { bus priority and multi-door articulated buses. }\end{array}$ \\
\hline 3 & 1996, AAMA & $\begin{array}{l}\text { BRTS suitable in fast growing urban area and also attract the } \\
\text { visitors towards public transport }\end{array}$ \\
\hline 4 & $\begin{array}{l}\text { 2003, TRB } \\
\text { (26 cities) }\end{array}$ & $\begin{array}{l}\text { New passengers attracted, } 30 \% \text { increase in use of public } \\
\text { transportation, made integral part in economic development }\end{array}$ \\
\hline 5 & $\begin{array}{l}2007 \\
\text { Vaishali M } \\
\text { Patankar }\end{array}$ & $\begin{array}{l}\text { BRTS play a significant role in development of sustainable } \\
\text { transport systems in congested area. }\end{array}$ \\
\hline 6 & $\begin{array}{l}\text { 2009, } \\
\text { P. Vedagiri }\end{array}$ & $\begin{array}{l}\text { Introduction of BRTS on urban corridor enhance good level of } \\
\text { service of bus as well as for other vehicles on the adjacent right of } \\
\text { way }\end{array}$ \\
\hline 7 & $\begin{array}{c}2014 \\
\text { Gautam Raj }\end{array}$ & $\begin{array}{l}\text { V/C ratio is beyond } 0.688 \text { than it creating traffic congestion in both } \\
\text { BRTS lane as well as in MV lane }\end{array}$ \\
\hline 8 & $\begin{array}{c}2012 \\
\text { Pavar Utsav }\end{array}$ & $\begin{array}{l}\text { Decrease in delay is observed at every intersection compared to } \\
\text { pre to post BRTS situation. }\end{array}$ \\
\hline 9 & $\begin{array}{c}2012 \\
\text { Chetan Patel }\end{array}$ & Access control arterial road give good level of service. \\
\hline 10 & $\begin{array}{c}2014 \\
\text { Rakesh Kumar }\end{array}$ & $\begin{array}{l}\text { Possible modal shift from private mode to proposed public transit } \\
\text { system was range from } 45 \% \text { to } 51 \% \text {. }\end{array}$ \\
\hline 11 & $\begin{array}{l}2014 \\
\begin{array}{c}\text { Bhanu Kireeti } \\
\text { chnda }\end{array}\end{array}$ & $\begin{array}{l}\text { Implement of BRTS and/or LRTS is observed beneficial to } \\
\text { improve level of service }\end{array}$ \\
\hline 12 & $\begin{array}{c}2016 \\
\text { Sampath Kumar }\end{array}$ & $\begin{array}{l}\text { After implementation of BRTS there is improvement in LOS F to } \\
\text { LOS B OR C }\end{array}$ \\
\hline
\end{tabular}

\section{References}

(2016). statics World helth organisation.

Barton-Ashman Associates. (1971, June). Milwaukee Area Transit Plan: A Mass Transit Technical Study. City and County of Milwaukee, Wisconsin,.

Bhanu kireeti chanda and maddali sai satya goutham. (2014). introduction to corridor selection and assessment for Bus Rapid Transit System (BRTS)in HYDRABAD. American Journal of Research And Science, . 
Chetan R. patel and DR. G.J.joshi . (2012). Capacity and LOS for urban arterial road in mixed traffic condition. Transport research arena. Elsevier.

Dipti Thanki. (2012). urban road network simulations using VISSIM : a case study of navrangpura area, Ahmedabad. GTU.

Dr.H.R.Varia, P. U. (2012). impact analysis of transportation project: a case study of narol-naroda BRTS corridor. Thesis from LDCE.

Dr.shivanand. (2014). bus raoid transit system experience from india future prespective.

Electricwala Fatima, Rakesh Kumar. (2014). Introduction of public bus transit in Indian cities. International Journal Of Sustainable Built Environment. Elsevier.

Guatam raj godavarthi, R. s. (2014). measuring the performance of bus rapid transit corridor based on volume by capacity ratio",, journal of transportation engineering. ASCE.

Harrington, P. R. (1937). A ComprehensiveLocal Transportation Plan for the City of . Chicago,.

L. Goodman. (1972). "Bus Rapid Transit Progress in the USA. Volume 6, Part 1, ARRBProceedings.

Levinson, H. S. (1973). Bus Use of Highways: State of the Art. National Research Council NCHRP Report 143. Highway Research Board.

Smpath kumar, v ranjit kumar,DR. M.kameshwararao . (2016, November). prilimanary assessment of Bus rapid transit sysytem for urban road. volume 4 issue 3, issn 2347-4718 International Journal for Technological Reserch on Enginerring .

Transit cooperative reserch programe, . (2003). case study in Bus rapid transit. TRB, volume 1.

V. thamiz arasan and P. vedagiri . (2010, march). simulating heterogamous traffic flow on road with and without bus lane. journal of urban planning and development,. ASCE.

Vaishali M. patanakar, Rakesh kumar, g. ( June 2007). “impact of bus rapid transit lanes on traffic and commuter mobility,,. journal of urban planning and development. ASCE,.

Vipul N. Prajapati,. (2010). Simulation of Heterogeneous traffic Intersection using VISSIM, . Dissertation, LDCE. GTU.

Wilbur Smith and Associates, . (1970). The Potential for BusRapid transit. American Automobile Manufacturers Association Detroit. 